Bangladesh J. Plant Taxon. 21(1): 1-12, 2014 (June)

(C) 2014 Bangladesh Association of Plant Taxonomists

\title{
RELATIONSHIPS OF ASTRAGALUS L. IN SECTION SESAMEI BASED ON MORPHOLOGICAL CRITERIA AND MOLECULAR MARKERS
}

\author{
SHERIF M. SharawY ${ }^{1,2}$ AND ABDELFATTAH BADR ${ }^{3}$ \\ Botany Department, Faculty of Science, Ain Shams University, Cairo, Egypt
}

Keywords: Astragalus; Fabaceae; ISSR; RAPD; Section Sesamei.

\begin{abstract}
The relationships among five species and two varieties of Astragalus L. in the section Sesamei (Fabaceae) from Egypt and Saudi Arabia have been reassessed based on morphological variation and molecular polymorphism as revealed by RAPD and ISSR fingerprinting. The analysis of morphological variation delimited the examined taxa into two groups; one comprising samples representing A. sinaicus, A. asterias and A. schimperi, and the other is comprised of two samples of $A$. stella and six samples representing $A$. tribuloides. The grouping of A. asterias and A. schimperi based on morphological criteria indicates affinities between them that were not reflected in their previous treatments. Both morphological criteria and molecular markers indicated considerable distance between the samples of A. stella and A. tribuloides. The multiform nature of $A$. tribuloides is confirmed as $A$. tribuloides var. mareoticus is clearly differentiated from the type $A$. tribuloides and $A$. tribuloides var. minutus.
\end{abstract}

\section{Introduction}

Astragalus L. is the largest and most diverse genus of all angiosperms with more than 2,500 species distributed in arid and temperate regions of the Northern Hemisphere and South America (Podlech, 2008). It is particularly abundant in south western (SW) and south central (SC) Asia, western North America and South America (Maassoumi, 1998). The centre of origin and diversity of the genus is the drier mountainous parts of SW and SC Asia and the Himalaya (Maassoumi, 1998; Wojciechowski, 2005). In Egypt, Astragalus is represented by 32 species (Boulos, 1999) and in Saudi Arabia by 25 species (Migahid, 1996). The species in both countries are distributed in different phytogeographical regions and are delimited in several sections.

In the first comprehensive classification of the genus Astragalus presented by Bunge (1868), the annual species were assigned to two subgenera, Trimeniaeus Bunge and Pogonophace Bunge based on glabrous and barbellate stigma, respectively. In that classification subgenus Trimeniaeus included most of the species while subgenus Pogonophace contained only seven species. In recent taxonomic treatments of the genus, all annual species of Astragalus in the Old World were classified under subgenus Trimeniaeus, which has been considered to be monophyletic (Taeb et al., 2007). Podlech (2008) classified the annual species of Astragalus into 14 sections including the section Sesamei DC. The section Sesamei is represented by five species in Egypt and five species in Saudi Arabia (Migahid, 1996; Boulos, 1999).

The molecular approaches to the taxonomy of Astragalus have been useful in constructing phylogenetic clades that help understand the evolutionary relationships and diversification in the genus (Wojciechowski, 2005; Kazempour Osaloo, et al., 2005). Wojciechowski et al. (1999) have shown that some of the species-rich sections are monophyletic but other works indicated that none of the subgenera and large sections of the genus are monophyletic (Kazempour Osaloo, et al., 2005).

\footnotetext{
${ }^{1}$ Corresponding author. E-mail: sherifsharaawy@yahoo.com

${ }^{1}$ Current Address: Biology department, Faculty of Science, Hail University, Hail, Saudi Arabia

${ }^{3}$ Botany and Microbiology Department, Faculty of Science, Helwan University, Cairo, Egypt
} 
Random amplified polymorphic DNA (RAPD) and Inter simple sequence repeat (ISSR) markers are used for detecting genetic variation and species relationships (Williams et al., 1990; Zietkiewicz et al., 1994). In the genus Astragalus L., RAPD and ISSR markers have been applied in recent studies at the intra- and inter-specific relationship. ISSRs were chosen to assess genetic differentiation among population of the endemic species Astragalus oniciformis Barneby in the upper Snake River Plain of central Idaho in the USA (Alexander et al., 2004). Intra- and interspecific relationships within the Astragalus microcephalus complex were studied using RAPD (Mehrina et al., 2005). High levels of genetic diversity were observed in three morphological types of Astragalus membranaceus (Fisch.) Bge. var. mongholicus (Bge.) Hsiao as revealed by ISSR (Xie et al., 2009). Comparative analysis of molecular diversity of Astragalus adsurgens germplasm from north China was made using RAPD and ISSR Markers (Huang et al., 2009). Anand et al. (2010) used ISSR, RAPD and DAMD (Directed amplification of mini-satellite DNA) to address the relationships among four closely related species of the Astragalus rhizanthus complex (i.e. A. rhizanthus, A. candolleanus, A. malacophyllus and A. pindreensis) from different parts of the Indian Himalaya and proved that these markers are potential to distinguish the closely allied species and to analyze the genetic diversity within and between the species of Astragalus. The objective of the present study is to clarify the systematic status of some taxa of Astragalus section Sesamei growing in Egypt and Saudi Arabia based on RAPD and ISSR polymorphism in addition to morphological variations.

\section{Materials and Methods}

\section{Plant materials and scoring of morphological traits}

The materials used in this study include 14 samples representing seven taxa of Astragalus section Sesamei collected from different localities in Egypt and Saudi Arabia (Table 1). The plant specimens have been identified following Boulos (1999) and Migahid (1996). The specimens of the examined taxa are deposited at the Herbarium of Botany Department, Faculty of Science, Ain Shams University, Cairo, Egypt and at the Museum of Biology Department, Faculty of Science, Hail University, Hail, Saudi Arabia.

A total of 45 morphological characters were considered, which include 32 two-state characters and 13 multi-state characters. The measurements and description of these characters were scored from at least five plants of each taxon. The characters and their states for morphological analysis are appended in Table 2.

\section{DNA extraction}

For DNA extraction, seeds of bulked samples of each of the studied taxa were germinated at $20^{\circ} \mathrm{C}$ for 15 days. Young seedlings were collected on ice and DNA was extracted from fresh young leaves using the CTAB method following the protocol of Saghai-Maroof et al. (1984).

\section{RAPD fingerprinting}

RAPD fingerprinting was performed using 20 arbitrary 10-mer random primers (Operon Technologies, Inc., USA). However, only ten primers gave clearly defined fingerprinting which are shown in Table 3. PCR was carried out using a Biocycler TC-S thermal cycler from HVD, Austria. The PCR reactions were developed in a total volume of $50 \mu \mathrm{l}$ with the following components: $5 \mu \mathrm{l}$ of $10 \mathrm{X}$ reaction buffer $(75 \mathrm{mM}$ Tris $\mathrm{HCl}, \mathrm{pH} 9.0,50 \mathrm{mM} \mathrm{KCl}, 20 \mathrm{nM}$ $\left(\mathrm{NH}_{4}\right)_{2} \mathrm{SO}_{4}$ and $0.001 \%$ bovine serum albumin), $2 \mu \mathrm{l}$ of $25 \mathrm{mM}$ of each primer, $1 \mu \mathrm{l}$ of Taq DNA polymerase $(1 \mathrm{U} / \mu \mathrm{l})$, and $2 \mu \mathrm{l}$ template DNA. The volume was completed to $50 \mu \mathrm{l}$ with deionizied diethylpyrocarbonate (DEPC) water. The following PCR program was used: an initial denaturation of DNA was carried out at $94^{\circ} \mathrm{C}$ for $1 \mathrm{~min}$, followed by 40 cycles of annealing at 
$37^{\circ} \mathrm{C}$ for $1 \mathrm{~min}$, extension at $72^{\circ} \mathrm{C}$ for $2 \mathrm{~min}$ and a final extension at $72^{\circ} \mathrm{C}$ for $7 \mathrm{~min}$. The RAPD products were resolved in $1.4 \%$ agarose gel in TAE buffer $(0.04 \mathrm{M}$ Tris-acetate, $1 \mathrm{mM}$ EDTA; $\mathrm{pH}=8)$ at 100 volt for $60 \mathrm{~min}$. A molecular size marker ranging from 530 to $1950 \mathrm{bp}$ was used to estimate the size of resolved RAPD products. The gels were stained in $0.2 \mu \mathrm{g} / \mathrm{ml}$ ethidium bromide and photographed using a gel documentation system (Gel Doc BioRad 2000). Each experiment was repeated twice and only stable bands were scored.

Table 1. List of Astragalus L. taxa of the section Sesamei examined along with their locality.

\begin{tabular}{cll}
\hline S1. No. & Taxon & Locality \\
\hline 1. & Astragalus asterias Stev. ex Ledeb. 1 & Burg El-Arab, Egypt \\
2. & A. asterias Stev. ex Ledeb. 2 & Hail-Al Jouf road, Saudi Arabia \\
3. & A. schimperi Boiss. 1 & Saint Catherine, South Sinai, Egypt \\
4. & A. schimperi Boiss. 2 & Aja Mountain, Hail, Saudi Arabia \\
5. & A. sinaicus Boiss. 1 & Wadi El Arish, North Sinai, Egypt \\
6. & A. sinaicus Boiss. 2 & Aja Mountain, Hail, Saudi Arabia \\
7. & A. stella L. 1 & Wadi El Arish, Sinai, Egypt \\
8. & A. stella L. 2 & Al Madinah-Makkah road, Saudi Arabia \\
9. & A. tribuloides Del. 1 & Alexandria-Matruh Road, Egypt \\
10. & A. tribuloides Del. 2 & Hail- Al Madinah road, Saudi Arabia \\
11. & A. tribuloides var. mareoticus Sirj. 1 & Alexandria-Matruh Road, Egypt \\
12. & A. tribuloides var. mareoticus Sirj. 2 & Hema Faid region, Hail, Saudi Arabia \\
13. & A. tribuloides var. minutus Boiss. 1 & Saint Catherine, South Sinai, Egypt \\
14. & A. tribuloides var. minutus Boiss. 2 & Al Madinah-Makkah road, Saudi Arabia \\
\hline
\end{tabular}

\section{ISSR fingerprinting}

Eight ISSR primers manufactured by the UBC (University of British Columbia, Canada) were used in the present study; the sequences of these primers are listed in Table 3. The amplification of ISSR markers was performed according to Nagoka and Ogihara (1997). The reaction mixture consisted of $12.5 \mu \mathrm{l}$ Hot Start Master Mixture, $2.0 \mu \mathrm{l}$ of primer $(10 \mathrm{mM}), 1.0 \mu 1$ of template DNA $(50 \mathrm{mg} / \mu \mathrm{l})$, and filled up to $25 \mu \mathrm{l}$ by $\mathrm{ddH}_{2} \mathrm{O}$. Amplification was carried out in a HVD thermocycler programmed as follows: 40 cycles after an initial cycle for $5 \mathrm{~min}$ at $94^{\circ} \mathrm{C}$ and each cycle consisted of a denaturation at $94^{\circ} \mathrm{C}$ for $2 \mathrm{~min}$, annealing at $36^{\circ} \mathrm{C}$ for $1 \mathrm{~min}$, extension at $72^{\circ} \mathrm{C}$ for $1 \mathrm{~min}$ followed by a final extension at $72^{\circ} \mathrm{C}$ for $7 \mathrm{~min}$. The ISSR products were resolved in $1.5 \%$ agarose gel in TAE buffer ( $0.04 \mathrm{M}$ Tris-acetate buffer, $\mathrm{pH}=8)$ at 100 volt for $60 \mathrm{~min}$. A 1 $\mathrm{kb}$ ladder was used as DNA molecular size standard. ISSR bands were visualized on UV-transilluminator and photographed using gel documentation system (Gel Doc-BioRad 2000). Each experiment was repeated twice and only stable bands were scored.

\section{Data analyses}

The relationship among the examined taxa was estimated based on differences among them in morphological traits as well as ISSR and RAPD fingerprinting separately and in combination. The morphological traits were given codes ranging between 0 and 3 depending on the variation in the average value for the measured traits (Table 2). The RAPD and ISSR bands were scored as ' 1 ' and ' 0 ' for presence or absence, respectively. In order to construct trees elucidating the relationships among the examined taxa, the coded data were analyzed using UPGMA (Sokal and Michener, 1958 ) and the Neighbor-joining (Saitou and Nei, 1987) methods based on a distance matrix. All analyses were performed with NTSYS-pc (Rohlf, 2000). 
Table 2. Morphological characters and their state used in the numerical analysis.

\begin{tabular}{|c|c|c|}
\hline No. & Characters & Characters states \\
\hline 1. & Habit & Erect herb $(0)$, prostrate herb $(1)$ \\
\hline 2. & Length $(\mathrm{cm})$ & $0-10(0), 10.1-20(1),>20(2)$ \\
\hline 3. & Stem hairness & Tomentose (0), canescent (1), appressed (2), villous (3) \\
\hline 4. & Colour of stem hairs & White (0), white and black (1) \\
\hline 5. & Stipule length $(\mathrm{cm})$ & $0.5(0), 0.51-1(1),>1(2)$ \\
\hline 6. & Stipule width $(\mathrm{cm})$ & $0.1-0.5(0),>0.5(1)$ \\
\hline 7. & Adnation of stipules & Free $(0)$, adnate $(1)$ \\
\hline 8. & Shape of stipules & Ovate $(0)$, lanceolate $(1)$, triangle (2) \\
\hline 9. & Stipule apex & Acute $(0)$, acuminate $(1)$ \\
\hline 10. & Stipule hairs & White $(0)$, white and black (1) \\
\hline 11. & Leaf length $(\mathrm{cm})$ & $1-10(0),>10(1)$ \\
\hline 12. & Leaf width $(\mathrm{cm})$ & $0.1-1(0),>1(1)$ \\
\hline 13. & Leaf rachis & Imparipinnate $(0)$, paripinnate $(1)$ \\
\hline 14. & Colour of leaf hairs & White (0), white and black (1) \\
\hline 15. & Leaflet length $(\mathrm{cm})$ & $<0.5(0), 0.51-1(1)$ \\
\hline 16. & Leaflet width $(\mathrm{cm})$ & $0.1-0.5(0),>0.5(1)$ \\
\hline 17. & Leaflet upper surface & Glabrous (0), hairy (1) \\
\hline 18. & Leaflet arrangement & Opposite $(0)$, alternate $(1)$ \\
\hline 19. & Leaflet shape & Ovate (0), elliptic (1), lanceolate (2) \\
\hline 20. & Leaflet apex & Obtuse ( 0$)$, acute (1), notched (2) \\
\hline 21. & Number of leaflets & $1-10(0), 11-20(1),>20(2)$ \\
\hline 22. & Inflorescence type & Raceme $(0)$, capitate $(1)$ \\
\hline 23. & Peduncle length (cm) & $0.1-5.0(0),>5(1)$ \\
\hline 24. & Inflorescence hairs & White $(0)$, black and white (1) \\
\hline 25. & Flower colour & White $(0)$, purple (1), violet (2) \\
\hline 26. & Flower length $(\mathrm{cm})$ & $0.1-1(0), 1.1-1.5(1),>1.5(2)$ \\
\hline 27. & Calyx length $(\mathrm{cm})$ & $<0.5(0), 0.51-1.0(1)$ \\
\hline 28. & Colour of calyx hairs & White (0), white and black (1), \\
\hline 29. & Stamen length $(\mathrm{cm})$ & $0.1-0.5(0), 0.5-1(1),>1(2)$ \\
\hline 30 . & Ovary length $(\mathrm{cm})$ & $0.1-0.5(0), 0.5-1(1),>1(2)$ \\
\hline 31. & Ovary width $(\mathrm{cm})$ & $0.1(0), 0.2(1)$ \\
\hline 32. & Pod length $(\mathrm{cm})$ & $0.1-2(0),>2(1)$ \\
\hline 33. & Pod width $(\mathrm{cm})$ & $0.1-0.5(0),>0.5(1)$ \\
\hline 34. & Pod pedicel & Absent (0), shorter than pod (1), longer than pod (2) \\
\hline 35. & Pod texture & Glabrous (0), hairy (1) \\
\hline 36. & Pod surface & Membranous (0), wrinkled (1) \\
\hline 37. & Pod dorsal suture & Obtuse (0), grooved (1), furrowed (2) \\
\hline 38. & Pod ventral suture & Obtuse $(0)$, furrowed (1) \\
\hline 39. & Pod apex & Acute $(0)$, beaked (1) \\
\hline 40. & Number of seeds & $1-10(0),>10(1)$ \\
\hline 41. & Seed length $(\mathrm{cm})$ & $0.1-0.2(0),>0.2(1)$ \\
\hline 42. & Seed width $(\mathrm{cm})$ & $0.1-0.2(0),>0.2(1)$ \\
\hline 43. & Seed shape & Reniform (0), quadrate (1) \\
\hline 44. & Seed colour & Yellow (0), brown (1) \\
\hline 45. & Seed surface & Smooth (0), Irregular (1) \\
\hline
\end{tabular}


Table 3. RAPD and ISSR primers used for DNA fingerprinting in Astragalus L. taxa.

\begin{tabular}{cccccc}
\hline & \multicolumn{2}{c}{ RAPD primers } & \multicolumn{2}{c}{ ISSR primers } \\
\hline No. & Primer code & Primer base sequence & No. & Primer code & Primer base sequence \\
\hline 1 & A14 & 5'TCT GTG CTGG 3' & 1 & UBC808 & $(\mathrm{AG})_{8} \mathrm{C}$ \\
2 & B17 & 5'AGG GAA CGAG 3' & 2 & UBC809 & $(\mathrm{AG})_{8} \mathrm{G}$ \\
3 & OPA01 & 5'CAG GCC CTTC 3' & 3 & UBC810 & $(\mathrm{GA})_{8} \mathrm{~T}$ \\
4 & OPB07 & 5'GCT GAC GCAG 3' & 4 & UBC812 & $(\mathrm{GA})_{8} \mathrm{~A}$ \\
5 & OPB20 & 5'GGA CCC TTAC 3' & 5 & UBC 830 & $(\mathrm{TG})_{8} \mathrm{G}$ \\
6 & F01 & 5'ACG GAT CCTG 3' & 6 & UBC840 & $(\mathrm{GA})_{8} \mathrm{CT}$ \\
7 & O04 & 5'AAG TCC GCTC 3' & 7 & UBC848 & $(\mathrm{CA})_{8} \mathrm{AG}$ \\
8 & O06 & 5'CCA CGG GAAG 3' & 8 & UBC855 & $(\mathrm{AC})_{8} \mathrm{CT}$ \\
9 & O08 & 5'CCT CCA GTGT 3' & & & \\
10 & O16 & 5'TCG GCG GTTC 3' & & \\
\hline
\end{tabular}

\section{Results and Discussion}

RAPD and ISSR fingerprinting analyses

A total of 91 RAPD bands were generated by 10 primers in 14 samples of Astragalus taxa investigated. Of these 68 bands are polymorphic and 23 are monomorphic. The polymorphic bands include 12 unique bands that have been revealed by seven primers (Table 4). The highest number of both total bands (20) and polymorphic bands (17) was produced by the primer OPB07. The RAPD fingerprints generated by the primer OPB07 is shown in Fig. 1. The primer A14, on the other hand, produced the highest number of monomorphic and unique bands (Table 4). The least number of bands (4 bands) was generated by two primers, namely $\mathrm{O} 04$ and $\mathrm{O} 08$; the number of polymorphic bands was 2 for the primer $\mathrm{O} 04$ and only 1 for the primer $\mathrm{O} 08$ with $50 \%$ and $25 \%$ polymorphism respectively (Table 4).

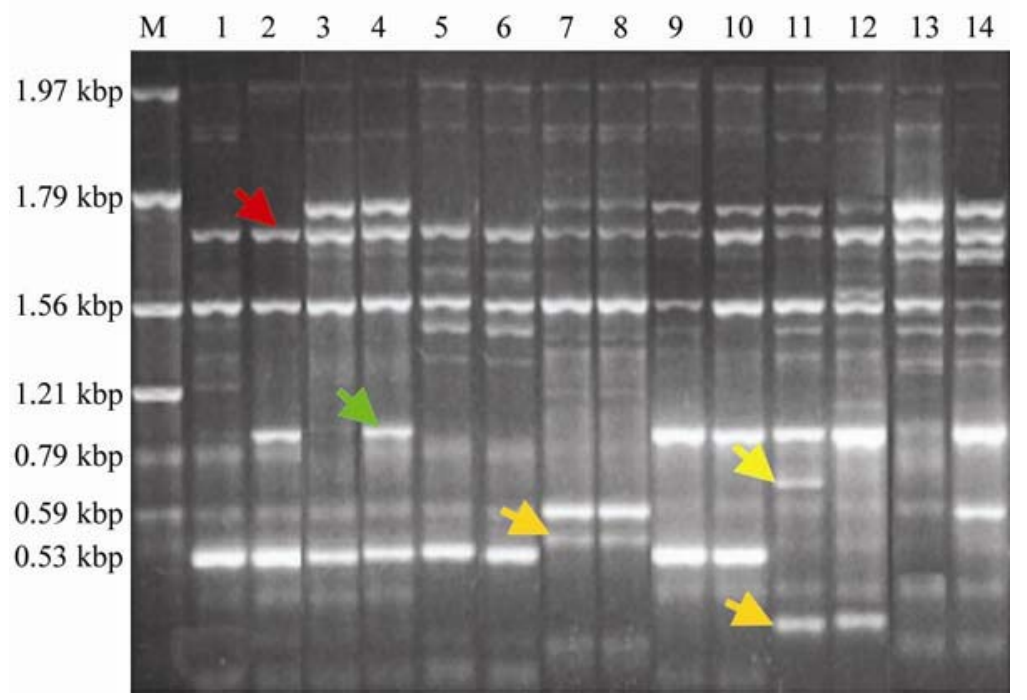

Fig. 1. RAPD fingerprints of the studied 14 samples of Astragalus L. as revealed by the primer OPB07. The lane to the left is a molecular size marker. Numbers on lanes 1-14 correspond to the serial numbers of samples as numbered in Table 1. First arrow indicates a monomorphic band, second arrow indicates polymorphic band, other arrows indicate unique band. 
The number of amplified bands generated by RAPD markers and their molecular size are given in Table 5. The primer A14 generated the highest number of bands ranging from 11 in A. stella and the varieties of $A$. tribuloides to 13 in A. schimperi and A. sinaicus. OPB07 generated a total of 121 bands ranging from 6 in A. asterias to 12 in A. tribuloides var. minutes. In contrast, the least number of bands were produced by the primer O06 (Table 5).

Table 4. Number and types of amplified RAPD bands generated in the examined 14 samples of Astragalus L.

\begin{tabular}{lccccccccccc}
\hline Types of bands & \multicolumn{10}{c}{ RAPD Primers and number of bands } \\
\cline { 2 - 12 } & A14 & B17 & OPA01 & OPB07 & OPB20 & F01 & O04 & O06 & O08 & O16 & Total \\
\hline Monomorphic & 4 & 2 & 3 & 2 & 2 & 3 & 2 & 1 & 3 & 1 & 23 \\
Unique & 4 & 1 & 1 & 1 & 2 & 0 & 0 & 1 & 0 & 1 & 11 \\
Polymorphic & 10 & 4 & 5 & 17 & 9 & 4 & 2 & 3 & 1 & 4 & 59 \\
Total bands & 18 & 7 & 9 & 20 & 13 & 7 & 4 & 5 & 4 & 6 & 93 \\
\% of polymorphism & 77.8 & 71.4 & 66.7 & 90 & 84.6 & 57.1 & 50 & 80 & 25 & 83.3 & 75.3 \\
\hline
\end{tabular}

Eight ISSR primers produced a total of 37 bands including only 14 polymorphic bands (Table 6; Fig. 2). The number of bands ranged from 3 as revealed by the three primers 809,848 and 855 to 7 revealed by the primer 810 ; all of the bands produced by the two primers 809 and 812 were monomorphic. The primer 830 (Fig. 2C) produced a band that in all taxa except the two samples

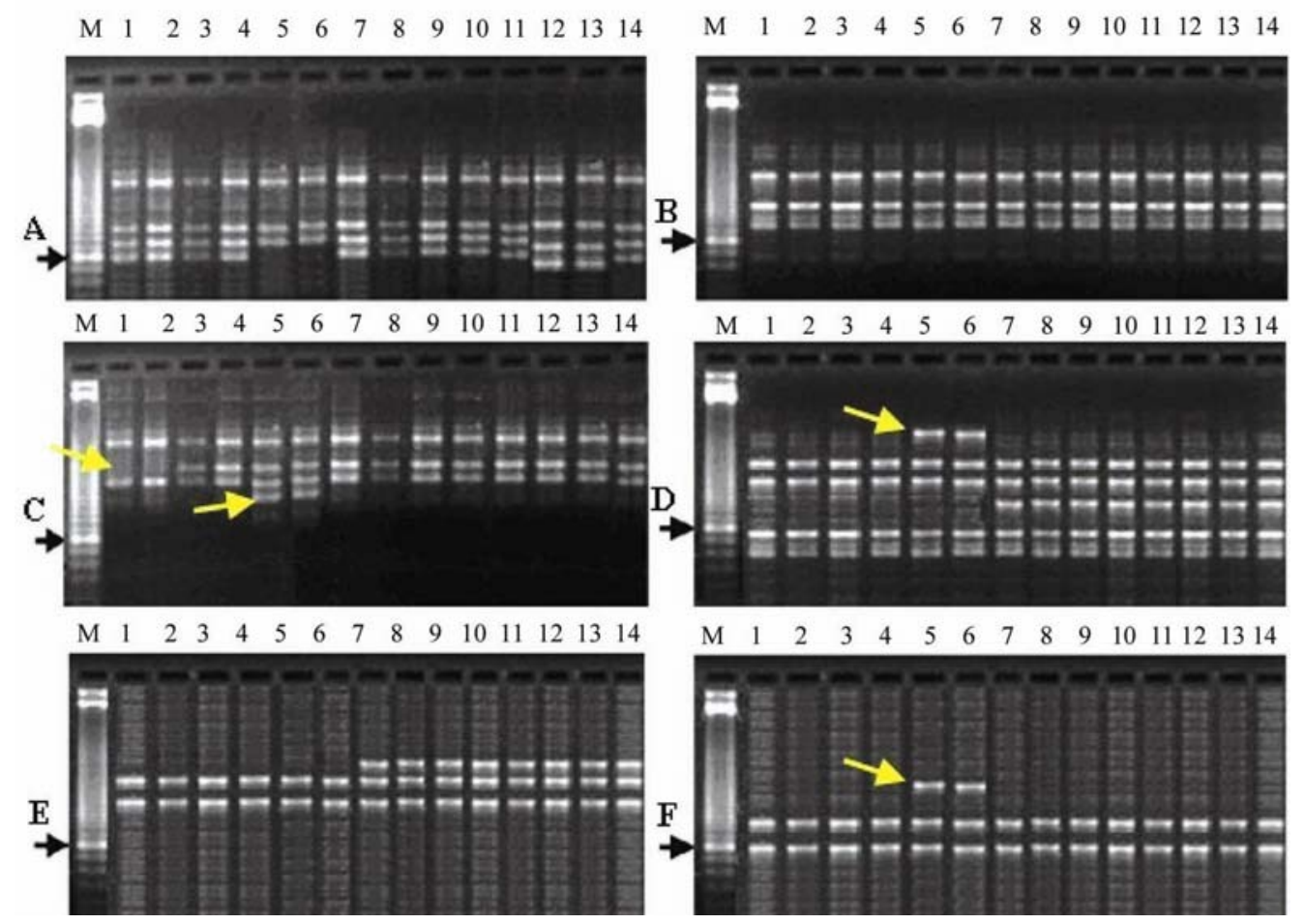

Fig. 2. ISSR fingerprints for 14 samples of Astragalus L. as revealed by six ISSR primers; primer codes are as follows: $\mathrm{A}=$ Primer UBC810, $\mathrm{B}=$ Primer UBC812, $\mathrm{C}=$ Primer UBC830, D = Primer UBC840, $\mathrm{E}=$ Primer UBC848, $\mathrm{F}=$ Primer UBC855 (see Table 4). Short arrows to the lane M indicate $250 \mathrm{bp}$ and long arrows shows bands unique to one species. Number on lanes 1-14 correspond to the serial numbers of Astragalus taxa as numbered in Table 1. 


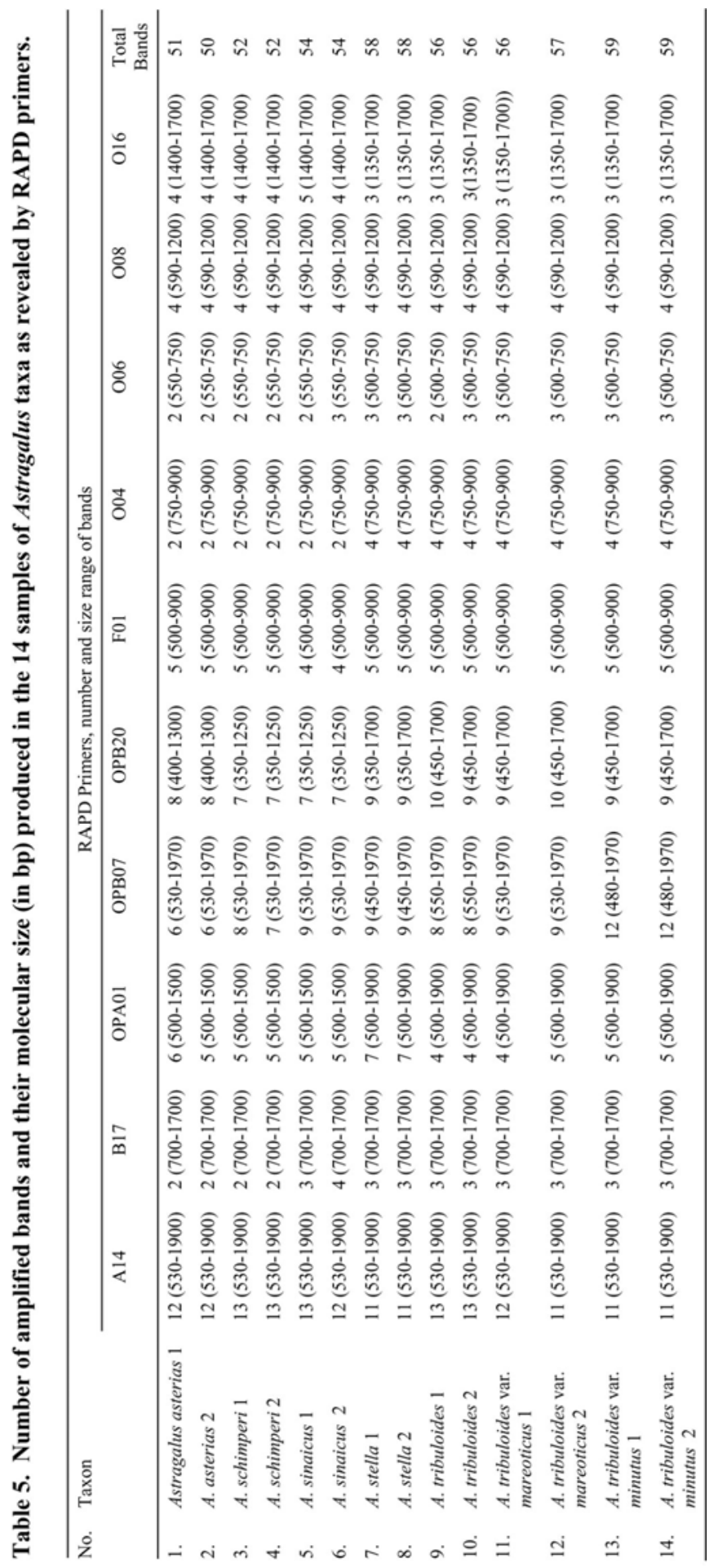


of A. asterias (lanes 1\&2); the same primer, produced a band in the profile A. sinaicus (lanes $5 \&$ 6) that were absent in the profile of other taxa. The two samples of the same species are also clearly distinguished by two bands in profile of primer 840 (Fig. 2D). In the profile of primer 848 (Fig. 2E), one band was evident in the ISSR profile of the two samples of A. stella (lanes 7-8) and the six samples representing the three varieties of $A$. tribuloides (lanes 9-14) and was absent from the profile of the taxa representing A. asterias, A. schimperi and A. sinaicus (lanes 1-6). In the profile of primer 855 (Fig. 2F), it is apparent that the ISSR profiling clearly differentiated $A$. sinaicus (lanes $5 \& 6$ ) by the presence of two bands that are absent in all other taxa. A glimpse on the ISSR profiling in all samples indicates that $A$. asterias (lanes 1-2) is characterized by the absence of one band in the profile of primer 830 (Fig. 2C) and A. sinaicus (lanes 5-6) is distinguished by presence of three unique bands in profile of primers 830,840 and 855 .

Table 6. Number and type of amplified bands generated by the eight primers in Astragalus section Sesamei.

\begin{tabular}{lccccccccc}
\hline \multirow{2}{*}{ Types of bands } & \multicolumn{8}{c}{ ISSR Primers and number of bands } & \multirow{2}{*}{ Total } \\
\cline { 2 - 7 } & 808 & 809 & 810 & 812 & 830 & 840 & 848 & 855 & \\
\hline Monomorphic & 4 & 3 & 2 & 4 & 2 & 4 & 2 & 2 & 23 \\
Unique & 0 & 0 & 0 & 0 & 0 & 0 & 0 & 0 & 0 \\
Polymorphic & 1 & 0 & 5 & 0 & 4 & 2 & 1 & 1 & 14 \\
Total bands & 5 & 3 & 7 & 4 & 6 & 6 & 3 & 3 & 37 \\
\% of polymorphism & 20 & 0 & 71.4 & 0 & 66.7 & 33.3 & 33.3 & 33.3 & 37.8 \\
\hline
\end{tabular}

Relationship among Astragalus taxa based on morphological variation:

The 14 samples of Astragalus are clearly divided into two groups in the UPGMA tree (Fig. 3), one comprising the taxa of A. sinaicus, A. asterias and A. schimperi and the other is comprised of taxa representing $A$. stella and the six samples representing $A$. tribuloides and its two varieties $A$. tribuloides var. mareoticus and $A$. tribuloides var. minutus. In the former group, the two samples of A. sinaicus are clearly delimited from the four samples representing A. asterias and A. schimperi. In the other group, the two samples representing A. stella are delimited from the other six samples representing A. tribuloides, A. tribuloides var. mareoticus and A. tribuloides var. minutus. The level of distance that separates the taxa of $A$. tribuloides exceeds the levels that separate the taxa representing A. asterias and A. schimperi (Fig. 3).

\section{Relationship among Astragalus taxa based on RAPD and ISSR polymorphism:}

The analyses of RAPD and ISSR data show that the two samples representing A. sinaicus are clearly delimited from the other taxa (Fig. 4). The other 12 samples are divided into two subgroups; one comprised of four samples representing the two species A. asterias and A. schimperi. The second subgroup includes the two samples representing A. stella and the six samples representing $A$. tribuloides. In this subgroup the two samples of the former species are clearly separated from the six samples representing A. tribuloides at the distance of 4.80 . The two samples representing $A$. tribuloides var. mareoticus are separated from the four samples representing A. tribuloides and A. tribuloides var. minutus at a distance of 3.70. The separation of the two samples representing A. sinaicus is clearly associated with the presence of three ISSR bands that are confined to material of this species and absent in the other taxa (Fig. 2C, D \& F). 


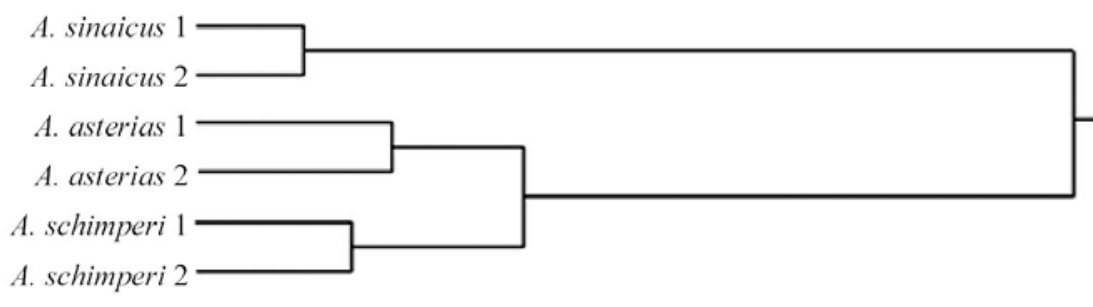

A. tribuloides var. mareoticus 1

A. tribuloides var. mareoticus 2

A. tribuloides 1

A. tribuloides

A. tribuloides var. minutus 1

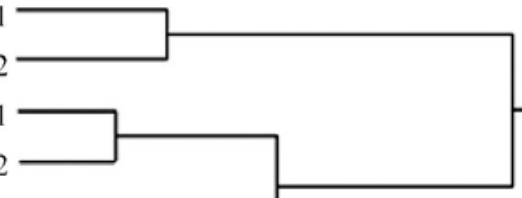

A. tribuloides var. minutus 2

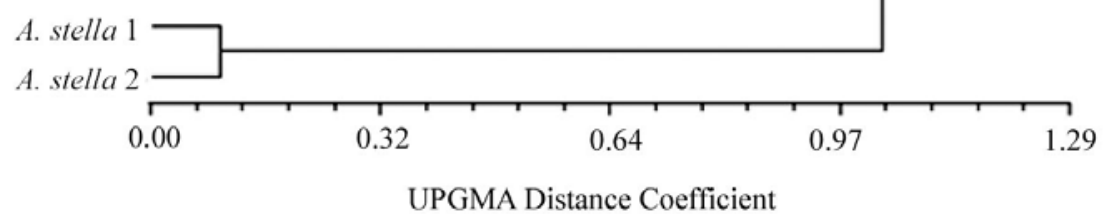

Fig. 3. UPGMA tree illustrating the relationships among Astragalus taxa based on morphological characters.

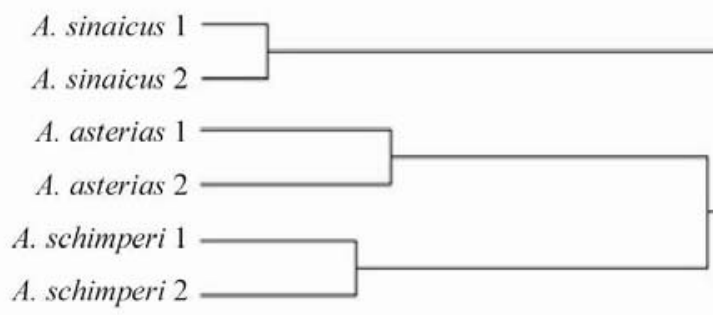

A. tribuloides var. mareoticus 1

A. tribuloides var. mareoticus 2

A. tribuloides 1

A. tribuloides 2

A. tribuloides var. minutus 1

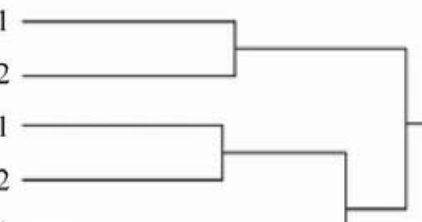

A. tribuloides var. minutus 2

$$
\begin{aligned}
& \text { A. stella } 1 \\
& \text { A. stella } 2
\end{aligned}
$$

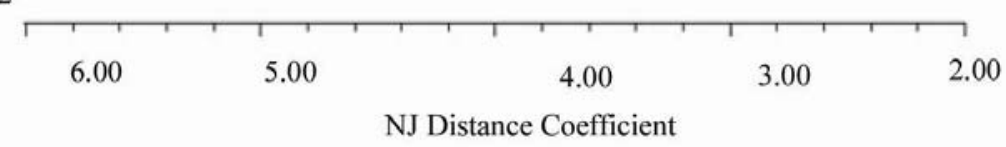

Fig. 4. Neighbour joining tree illustrating the relationships among Astragalus taxa based on RAPD and ISSR markers. 
Relationship among Astragalus taxa based on morphological variation and molecular polymorphism:

Relationships among Astragalus taxa studied based on morphological variation and molecular polymorphism is shown in the UPGMA tree (Fig. 5). In this tree, the two samples representing A. sinaicus are clearly delimited from the other taxa. The other 12 taxa are clearly divided into two groups at a distance of 1.15, one comprising the four taxa of A. asterias and A. schimperi and the other is comprised of the two samples representing A. stella and the six samples representing $A$. tribuloides. It is noted that the two samples of A. schimperi, in the first group, are delimited at a relatively high distance of 0.81 indicating considerable morphological variation among material of this species from Egypt and Saudi Arabia. In the other group, the two samples representing $A$. stella are delimited from the other six samples representing A. tribuloides, A. tribuloides var. mareoticus, A. tribuloides var. minutus at a distance of 1.15 on the distance scale. The two samples of $A$. stella are also distinguished from each other at a distance of 0.70 indicating considerable variation among material of this species from Egypt and Saudi Arabia.

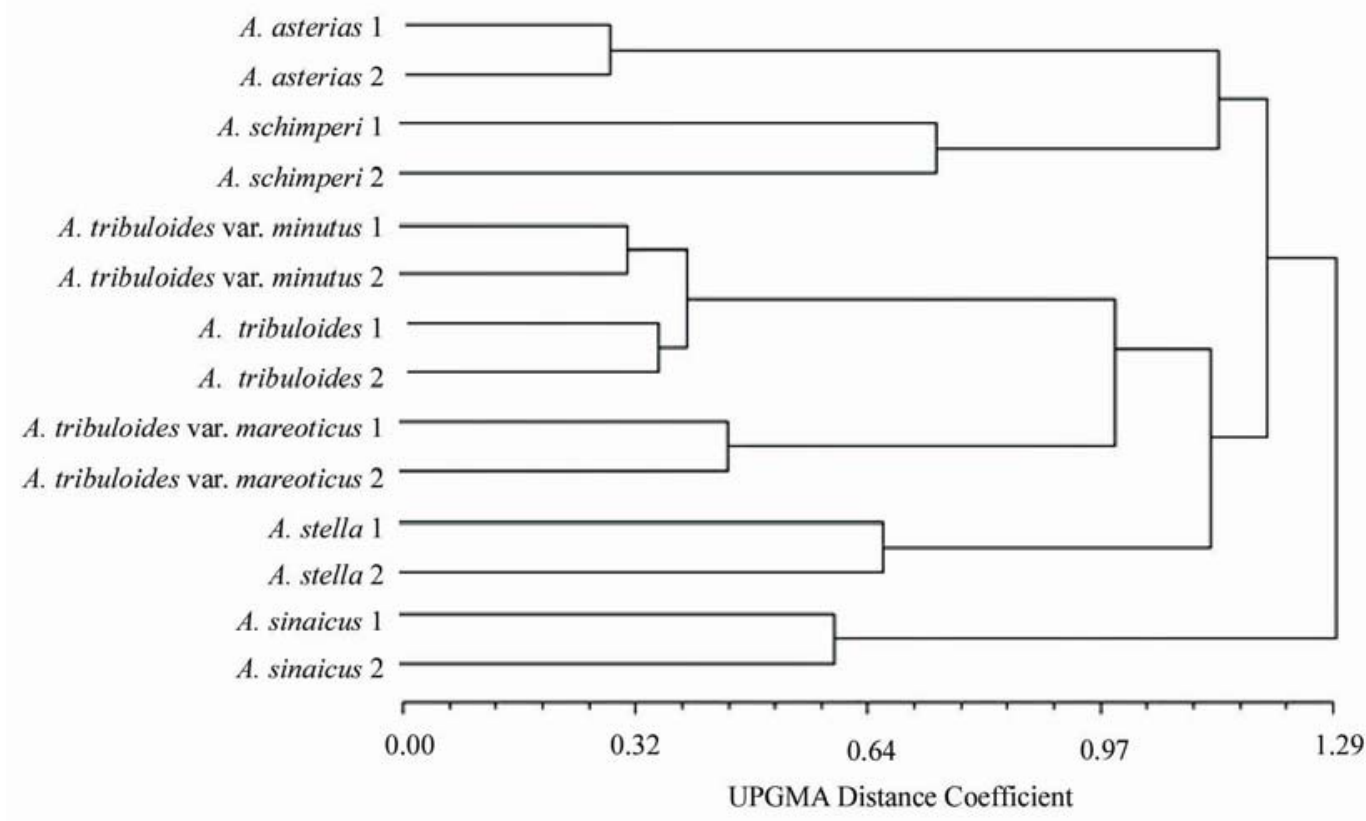

Fig. 5. UPGMA tree showing the relationships among Astragalus taxa based on morphological characters and molecular markers.

Podlech (1991) suggested that A. sinaicus is not existent in Egypt and assumed that the type may be from Greece and was erroneously attributed to Sinai by Boissier (1872) and may be considered as A. tribuloides which is a multiform species. This view was contradicted by Sharawy (2001) based on evidence derived from morphological and anatomical characters. Astragalus sinaicus was also clearly distinguished from the species of section Sesamei including A. stella, based on cytological evidence, as it has longer chromosomes and more symmetric karyotype compared to the other species (Badr and Sharawy, 2007). The analysis of morphological variation in the present study delimited A. sinaicus in a major group that also includes A. asterias and A. schimperi but remained distinguished as a separate identity. The distinction of this species is also clearly reflected in the relationship based of the analysis of ISSR and RAPD fingerprinting polymorphism. 
The grouping of $A$. asterias and A. schimperi based on morphological variation and molecular polymorphism is congruent with their grouping together based on the analysis of seed protein electrophoretic profile (Al-Nowaihi et al., 2002). However, evidence from seed protein electrophoretic analysis also indicated the grouping of A. asterias with A. tribuloides (Al-Nowaihi et al., 2002) that is not supported by molecular evidences expressed by the analysis of morphological variation and molecular polymorphism which is correlated with similarities between these two species in spermoderm characteristics (Sharawy, 2001). A. asterias possesses sessile leaves and fruits with double indumentum (Sharawy et al., 2003) that distinguish it from other species in section Sesamei, which can also be distinguished based on pollen characters (Saad and Taia, 1988).

Gazer (1993) divided the species of section Sesamei into four groups; i.e. Astragalus asterias group, A. schimperi group, A. sinaicus group and A. stella group; the latter group also comprised $A$. tribuloides. In the present investigation, the recognition of $A$. sinaicus and $A$. stella as distinct groups is supported by the relationships as expressed in the UPGMA trees based on morphological and molecular evidences. Both morphological criteria and molecular markers indicated considerable distance between the two samples of $A$. stella and the six samples of $A$. tribuloides and its two varieties, i.e. A. tribuloides var. mareoticus and A. tribuloides var. minutus. The distance levels among these varieties confirm the observations by Boissier (1872) and Podlech (1986) that $A$. tribuloides is a multiform species. In the present investigation A. tribuloides var. mareoticus is clearly distinct from A. tribuloides and A. tribuloides var. minutus.

\section{References}

Alexander, J.A., Liston, A. and Popovich, S.J. 2004. Genetic diversity of the narrow endemic Astragalus oniciformis (Fabaceae). Am. J. Bot. 91: 2004-2012.

Al-Nowaihi, A.S., Khalifa, S.F., Badr, A. and Sharawy, S.M. 2002. Species relationships of Astragalus L. in Egypt based on storage seed protein electrophoretic criteria. Proc. $2^{\text {nd }}$. Int. Conf. Biol. Sci. Faculty of Science, Tanta University 2: 174-188.

Anand, K.K., Srivastava, R.K., Chaudhary, L.B. and Singh, AK.I. 2010. Delimitation of species of the Astragalus rhizanthus complex (Fabaceae) using molecular markers RAPD, ISSR and DAMD. Taiwania 55: 197-207.

Badr, A. and Sharawy, S.M. 2007. Karyotype analysis and systematic relationships in the Egyptian Astragalus L. (Fabaceae). International J. Bot. 3: 147-159.

Boissier, E. 1872. Flora Orientals, Vol. 2. Genevae and Basiliae, Lugduni.

Boulos, L. 1999. Flora of Egypt 1: 320-336. Al-Hadara Publishing, Cairo, Egypt.

Bunge, A. 1868. Generis Astragali species Gerontogeae, Pars prior. Claves diagnosticae. Mém. Acad. Imp. Sci. St. Pétersb. 11: 1-140.

Gazer, M. 1993. Revision of Astragalus L. Sect. Sesamei DC. (Leguminosae). Sendtnera 1: 69-155.

Huang, L., Chen, Z. and Zhang, X. 2009. A comparative analysis of molecular diversity of erect milkvetch (Astragalus adsurgens) germplasm from north China using RAPD and ISSR markers. Biochem. Genet. 47: 92-99.

Kazempour Osaloo, S., Maassoumi, A.A. and Murakami, N. 2005. Molecular systematics of the Old World Astragalus (Fabaceae) as inferred from nrDNA ITS sequence data. Brittonia 57: 367-381.

Maassoumi, A.A. 1998. Astragalus L. in the World. Research Institute of Forests and Rangelands, Tehran, Iran.

Mehrnia, M., Zarre, S. and Sokhan-Sanj, A. 2005. Intra- and interspecific relationships within the Astragalus microcephalus complex (Fabaceae) using RAPD. Biochem. Syst. Ecol. 33: 149-158.

Migahid, A.M. 1996. Flora of Saudi Arabia. $4^{\text {th }}$ ed. King Saud University, Riyadh.

Nagoka, T. and Ogihara, Y. 1997. Applicability of inter-simple sequence repeat polymorphisms in wheat for use as DNA markers in comparison to RFLP and RAPD markers. Theor. Appl. Genet. 94: 597-602. 
Podlech, D. 1986. Taxonomic and phytogeographical problems in Astragalus of the Old World and southwest Asia. Proc. Royal Soc. Edinburgh 89: 37-43.

Podlech, D. 1991. The systematics of annual species of the genus Astragalus L. (Leguminosae). Flora et Vegetatio Mundi 9: 1-18.

Podlech, D. 2008. The genus Astragalus L. (Fabaceae) in Europe with exclusion of the former Soviet Union. Feddes Repertorium 119: 310-387.

Rohlf, F.J. 2000. NTSYS-pc: Numerical Taxonomy System. Ver. 2.1. Exeter Publishing, Ltd. Setauket, New York.

Saad, S.I. and Taia, W.K. 1988. Palynological studies of some species in the genus Astragalus L. Leguminosae in Egypt. Arab. Gulf. J. Sci. Res. B6: 227-243.

Saghai-Maroof, M.A., Soliman, K.M., Jorgensen, R.A. and Allard, R.W. 1984. Ribosomal DNA spacerlength polymorphisms in barly mendelian inheritance, chromosomal location and population dynamics. Proc. Natl. Acad. Sci. USA 81: 8014-8018.

Saitou, N. and Nei, M. 1987. The neighbor-joining method: a new method for reconstruction phylogenetic trees. Mol. Biol. Evol. 4: 40-42.

Sharawy, S.M. 2001. Taxonomic studies on interspecific and infraspecific relationships in the genus Astragalus in Egypt. Ph.D. Thesis, Ain Shams University, Cairo, Egypt.

Sharawy, S.M., Mourad, M.M. and Al-Nowaihi, A.S. 2003. The assessment of the morpho-anatomical characters of the spermoderm in delimitation of some Astragalus taxa growing in Egypt. Bull. Fac. Sci. Assiut. Univ. 32: 325-346.

Sokal, R.R. and Michener, C.D. 1958. A statistical method for evaluating systematic relationships. Univ. Kansas Sci. Bull. 28: 1409-1438.

Taeb, F., Zarre, S., Podlech, D., Tillich, H., Kazempour Osaloo, S. and Maassoumi, A. 2007. A contribution to the phylogeny of annual species of Astragalus (Fabaceae) in the Old World using hair micromorphology and other morphological characters. Feddes Repertorium 118: 206-227.

Williams, J.G.K., Kubelik, A.R., Livak, K.J., Rafalski, J.A. and Tingey, S.V. 1990. DNA polymorphisms amplified by arbitrary primers are useful as genetic markers. Nucleic Acids Research 18: 6531-6535.

Wojciechowski, M.F., Sanderson, M.J. and Hu, J.M. 1999. Evidence on the monophyly of Astragalus (Fabaceae) and its major subgroups based on nuclear ribosomal DNA ITS and chloroplast DNA trnL intron data. Systematic Botany 24: 409-437.

Wojciechowski, M.F. 2005. Astragalus (Fabaceae): a molecular phylogenetic perspective. Brittonia 57: 382396.

Xie, X., Hu, Y., Wang, L., Yang, J., Li, Y. and Peng, M. 2009. Genetic diversity in three morphological types of Astragalus membranaceus (Fisch.) Bge. var. mongholicus (Bge.) Hsiao as revealed by inter simple sequence repeat markers. African J. Biotech. 8: 4490-4494.

Zietkiewicz, E., Rafalski, A. and Labuda, D. 1994. Genome fingerprinting by simple sequence repeat (SSR) anchored polymerase chain reaction amplification. Genetics 20: 176-183.

(Manuscript received on 4 January 2013; revised on 8 May 2014) 